\title{
Structural, Chemical and Low Temperature Magnetic Properties of Lead Free 0.6NiFe204 - 0.4Na0.5Bi0.5TiO3 Magnetoelectric Composite
}

\section{G Jegadish Kumar}

SRM Institute of Science and Technology

\section{Sarathbavan}

SRM Institute of Science and Technology

\section{E Senthil Kumar}

SRM Institute of Science and Technology

\section{Navaneethan}

SRM Institute of Science and Technology

K Kamala Bharathi ( $\boldsymbol{\nabla}$ kamalabk@srmist.edu.in )

SRM Institute of Science and Technology https://orcid.org/0000-0002-8466-9400

\section{Research Article}

Keywords: NiFe2O4-Na0.5Bi0.5TiO3 composite, Magnetocrystalline anisotropy, Magnetization, Zero field cooled magnetization, Field cooled magnetization

Posted Date: February 12th, 2021

DOl: https://doi.org/10.21203/rs.3.rs-214261/v1

License: (1) This work is licensed under a Creative Commons Attribution 4.0 International License.

Read Full License

Version of Record: A version of this preprint was published at Journal of Materials Science: Materials in Electronics on May 28th, 2021. See the published version at https://doi.org/10.1007/s10854-021-06184$y$. 


\title{
Structural, Chemical and Low Temperature Magnetic Properties of Lead Free 0.6 $\mathrm{NiFe}_{2} \mathrm{O}_{4}$ - 0.4Na ${ }_{0.5} \mathrm{Bi}_{0.5} \mathrm{TiO}_{3}$ Magnetoelectric Composite
}

\author{
G. Jagadish Kumar ${ }^{\mathrm{a}}$, M. Sarathbavan ${ }^{\mathrm{b}}$, E. Senthil Kumar ${ }^{\mathrm{a}, \mathrm{b}}$, M. Navaneethan ${ }^{\mathrm{a}, \mathrm{b}}$, K. Kamala \\ Bharathi $^{\mathrm{a}, \mathrm{b}, *}$
}

${ }^{a}$ Nanotechnology Research Center (NRC), Faculty of Engineering and Technology, SRM Institute of Science and Technology, Kattankulathur, Chennai 603203, Tamil Nadu, India

${ }^{b}$ Department of Physics and Nanotechnology, SRM Institute of Science and Technology, Kattankulathur, Chennai 603203, Tamil Nadu, India

*corresponding author: kamalabk@srmist.edu.in (K. Kamala Bharathi) 


\begin{abstract}
We report on structural, chemical and low temperature magnetic properties of lead free $0.6 \mathrm{NiFe}_{2} \mathrm{O}_{4}-0.4 \mathrm{Na} 0.5 \mathrm{Bi} 0.5 \mathrm{TiO}_{3}$ composite. $\mathrm{NiFe}_{2} \mathrm{O}_{4}(\mathrm{NFO})$ and $\mathrm{Na}_{0.5} \mathrm{Bi}_{0.5} \mathrm{TiO}_{3}(\mathrm{NBTO})$ are seen to crystallize in inverse spinel and perovskite structure respectively. $0.6 \mathrm{NiFe}_{2} \mathrm{O}_{4}$ $0.4 \mathrm{Na} 0.5 \mathrm{Bi}_{0.5} \mathrm{TiO}_{3}$ composite exhibits both NFO and NBTO phases in appropriate composition. Zero field cooled (ZFC) and field cooled (FC) magnetization measurements carried out from 15 $\mathrm{K}$ to $300 \mathrm{~K}$ shows a large bifurcation at room temperature. ZFC and FC magnetization measurement exhibit a hump at $\mathrm{T}_{\mathrm{m}} \sim 259.5 \mathrm{~K}$, indicates the possible existence of competing magnetic interactions in $0.6 \mathrm{NiFe}_{2} \mathrm{O}_{4}-0.4 \mathrm{Na} 0.5 \mathrm{Bi} 0.5 \mathrm{TiO}_{3}$ composite. Saturation magnetization, remanent magnetization and coercivity values are observed to increase with decreasing the temperature. Temperature dependent saturation magnetization is fit to the Bloch's law. Magnetocrystalline anisotropy $\left(K_{l}\right)$ value at various temperatures are estimated and is seen to increase from $0.23 \times 10^{4} \mathrm{erg} / \mathrm{cc}$ (at $300 \mathrm{~K}$ ) to $0.34 \times 10^{4} \mathrm{erg} / \mathrm{cc}$ (at $15 \mathrm{~K}$ ).
\end{abstract}

Key words: $\mathrm{NiFe}_{2} \mathrm{O}_{4}-\mathrm{Na} 0.5 \mathrm{Bi}_{0.5} \mathrm{TiO}_{3}$ composite; Magnetocrystalline anisotropy; Magnetization; Zero field cooled magnetization; Field cooled magnetization 


\section{Introduction}

Multiferroic materials exhibit more than one ferroic property, which make them highly suitable for applications in spintronics, data storage devices, processors, controllers and sensors [1-3]. The multiferroic magntoelectric (ME) materials show both ferroelectric and ferromagnetic ordering simultaneously. The first magnetoelectic effect was reported in single crystal $\mathrm{Cr}_{2} \mathrm{O}_{3}$ compound in 1961 [4]. Several single phase ME materials with weak ME coupling have been reported in the literature by various research groups [5]. Composite ME materials have been developed by combining various oxides consisting of ferroelectric and ferro/antiferro magnetic ordering with considerable amount of coupling between their order parameters. Composites with various ratios of magnetic and electric components provide material designers to control the piezoelectric and magnetoelectirc properties tactically. The idea of composite ME materials overcome the difficulty of coexistence of ferroelectric and ferro/anti-ferromagnetic ordering in a single phase material [6,7]. The magnetoelectric composite consisting of $\mathrm{BaTiO}_{3}$ and $\mathrm{Ni}(\mathrm{Co}$, $\mathrm{Mn}) \mathrm{Fe}_{2} \mathrm{O}_{4}$ prepared by unidirectional solidification show two order high ME coefficient at room temperature than single phase $\mathrm{Cr}_{2} \mathrm{O}_{3}$ [8]. For the past several years, there is a tremendous advancement in design, production and application of ME composites. Many research groups have produced enormous lead $(\mathrm{Pb})$ based $\left(\mathrm{PbZr}_{1-\mathrm{x}} \mathrm{Ti}_{\mathrm{x}} \mathrm{O}_{3}, \mathrm{PbTiO}_{3}\right) \mathrm{ME}$ composites, which show higher ME coefficient than those of single-phase materials at room temperature [9-11]. However, due to their toxic nature, $\mathrm{Pb}$ based materials and composites are not encouraged for practical applications. After the ground-breaking experiments on $\mathrm{BaTiO}_{3} / \mathrm{CoFe}_{2} \mathrm{O}_{4}$ composite, a wide range of ferroelectric/ferrite bulk composites have been developed consisting of ferroelectric phases such as $\mathrm{BaTiO}_{3}, \mathrm{~N}_{0.5} \mathrm{~B}_{0.5} \mathrm{TiO}_{3}$, PZT and ferromagnetic phases such as $\mathrm{CoFe}_{2} \mathrm{O}_{4}, \mathrm{NiFe}_{2} \mathrm{O}_{4}$ and $\mathrm{CuFe}_{2} \mathrm{O}_{4}$ [12-16]. $\mathrm{NiFe}_{2} \mathrm{O}_{4}-\mathrm{PbZ}_{0.52} \mathrm{Ti}_{0.48} \mathrm{O}_{3}$ exhibits resonance magnetoelectric effect in 
which magnetoelectric resonances are caused by electromechanical resonance in the peizelectric phase and magneto-chemical resonance in the magntostrictive phase [17]. The $\mathrm{Na}_{0.5} \mathrm{Bii}_{0.5} \mathrm{TiO}_{3}-$ $\mathrm{NiFe}_{2} \mathrm{O}_{4}$ (NBTO-NFO) composite consisting of ferroelectric NBTO [18-19] and NFO soft magnetic material with low coercivity and high electric resistivity show high ME response. [20]. Electrostatically tunable ferromagnetic resonance and large converse magnetoelectric coupling (109 Oe-cm k V${ }^{-1}$ ) are observed in $\mathrm{Na}_{0.5} \mathrm{Bi}_{0.5} \mathrm{TiO}_{3}-\mathrm{CoFe}_{2} \mathrm{O}_{4}$ lead-free multiferroic composite [21,22]. Narendra et. al. have reported the highest $\mathrm{ME}$ response of $0.14 \%$ at $1 \mathrm{MHz}$ in a magnetic field from 0 to $6 \mathrm{kOe}$ for $0.67 \mathrm{NiFe}_{2} \mathrm{O}_{4}-0.33 \mathrm{Na}_{0.5} \mathrm{Bi}_{0.5} \mathrm{TiO}_{3}$ [23].

In the present case, detailed studies on structural, micro-structural, chemical and magnetic properties of bulk $0.6 \mathrm{NiFe}_{2} \mathrm{O}_{4}-0.4 \mathrm{Na} 0.5 \mathrm{Bi} 0.5 \mathrm{TiO}_{3}$ composite have been explored. Interestingly, the ZFC and FC magnetization measurement shows the possibility of existence of competing magnetic interactions at low temperatures and irreversibility at room temperature. Various magnetic properties are estimated at different temperatures and the temperature dependent saturation magnetization values are analyzed using Block's law. Anisotropy constant value at different temperature is estimated using single ion model. The observed temperature dependent magnetic properties, structural and chemical properties of $0.6 \mathrm{NiFe}_{2} \mathrm{O}_{4}$ $0.4 \mathrm{Na} 0.5 \mathrm{Bi}_{0.5} \mathrm{TiO}_{3}$ composite is discussed and reported in this manuscript.

\section{Experimental details}

Pure $\mathrm{NiFe}_{2} \mathrm{O}_{4}$ was prepared using high quality powders of $\mathrm{NiO}$ and $\mathrm{Fe}_{2} \mathrm{O}_{3}$ (99.9\% Sigma-aldrich) taken according to the stoichiometric ratio and grounded well using mortar and pestle for $2 \mathrm{hr}$. The homogeneous mixture was calcinated at $800{ }^{\circ} \mathrm{C}$ for $5 \mathrm{hr}$. The calcined powder was finely reground for $1 \mathrm{hr}$ followed by $3 \mathrm{hr}$ sintering at $1050^{\circ} \mathrm{C}$. Similarly, pure sodium bismuth titanate $\mathrm{Na} 0.5 \mathrm{Bi} 0.5 \mathrm{TiO}_{3}$ was synthesized by thoroughly mixing high pure $\mathrm{Na}_{2} \mathrm{CO}_{3}, \mathrm{Bi}_{2} \mathrm{O}_{3}, \mathrm{TiO}_{2}$ powders 
(99.9\%, Sigma-aldrich) according to the stoichiometric ratio. The mixed powder was calcinated at $950^{\circ} \mathrm{C}$ for $3 \mathrm{hr}$. Pure and homogeneous powders of NFO and NBTO were mixed in the ratio of 60:40 Wt. \% respectively for $1 \mathrm{hr}$ to obtain the composite of the $0.6 \mathrm{NiFe}_{2} \mathrm{O}_{4}-0.4 \mathrm{Na} 0.5 \mathrm{Bi} 0.5 \mathrm{TiO}_{3}$. The formation of pure phase of the prepared samples and the structural analysis were performed at room temperature (RT) using X-ray diffraction (XRD) (Make: PANanalytic Xpert Pro) using $\mathrm{Cu} \mathrm{k}_{\alpha}$ radiation $(\lambda=1.540 \AA)$. Morphology and particle size were investigated using field emission scanning electron microscope (FE-SEM, Make: FEI QUANTA-200, USA) with an applied voltage of $20 \mathrm{kV}$. The micro-analysis and oxidation states of all the elements present in the NFO, NBTO and $0.6 \mathrm{NiFe}_{2} \mathrm{O}_{4}-0.4 \mathrm{Na} 0.5 \mathrm{Bi}_{0.5} \mathrm{TiO}_{3}$ are investigated using $\mathrm{X}$ - ray photoelectron spectroscopy (XPS) (Make: ULVAC-PHI VersaProbe III) with X-ray source of Al and photon energy of $1486.6 \mathrm{eV}$. The core elemental spectra of XPS date are fitted using mixed Gaussian and Lorentzian functions XPSPeakfit 4.1 software. Further, the Raman spectroscopy which a powerful tool to examine the structural characteristics was employed at room temperature using a micro-Raman spectrometer (Make: LabRAM HR Evolution, HORIBA, France) in a backscattering configuration with the laser focused to a $1 \mu \mathrm{m}^{2}$ spot. The laser wavelength used was $532 \mathrm{~nm}$ with a total power of $5 \mathrm{~mW}$. The temperature and field dependent magnetic measurements were carried out using vibrating sample magnetometer (VSM) (Make: Lakeshore 7400-S, USA) by varying the field up to $15 \mathrm{kOe}$ in the temperature range of $15 \mathrm{~K}$ to $300 \mathrm{~K}$.

\section{Results and Discussion}

Figure 1 (a) to (c) shows the $\mathrm{XRD}$ patterns of $\mathrm{NiFe}_{2} \mathrm{O}_{4}, \mathrm{Na}_{0.5} \mathrm{Bi}_{0.5} \mathrm{TiO}_{3}$ and the composite $0.6 \mathrm{NiFe}_{2} \mathrm{O}_{4}-0.4(\mathrm{Na} 0.5 \mathrm{Bi} 0.5) \mathrm{TiO}_{3}$ respectively. The $\mathrm{XRD}$ pattern of parent phases and the composite shows sharp and well-defined peaks at appropriate positions without any peaks corresponding to impurity phases. The XRD pattern of $\mathrm{NiFe}_{2} \mathrm{O}_{4}$ is indexed by considering the 
cubic spinel structure and is in good agreement with standard JCPDS card (\# 89-4927). The lattice parameter values $\mathrm{a}=\mathrm{b}=\mathrm{c}=8.35 \AA$ is observed to agree well with the reported value [24]. $\mathrm{Na} 0.5 \mathrm{Bi} 0.5 \mathrm{TiO}_{3}$ is seen to crystallize in rhombohedral phase with the lattice paramenter values of a $=\mathrm{b}=5.4 \AA$ and $\mathrm{c}=13.5 \AA$, matches well with reported value (JCPDS card (\#36-3040)). The composite $0.6 \mathrm{NiFe}_{2} \mathrm{O}_{4}-0.4\left(\mathrm{Na}_{0.5} \mathrm{Bi}_{0.5}\right) \mathrm{TiO}_{3}$ shows the coexistence of maximum intense peaks corresponding to $\mathrm{NiFe}_{2} \mathrm{O}_{4}$ and $\mathrm{Na}_{0.5} \mathrm{Bi}_{0.5} \mathrm{TiO}_{3}$ phases and other common peaks confirms the presence of both phases without any distortion. No extra peaks or peak splitting is observed which removes the possibility of transition from rhombohedral to tetragonal phase.

Figure 2 (a) to (c) shows the scanning electron micrographs (SEM) images of $\mathrm{NiFe}_{2} \mathrm{O}_{4}$, $\mathrm{Na} 0.5 \mathrm{Bi}_{0.5} \mathrm{TiO}_{3}$ and the composite $0.6 \mathrm{NiFe}_{2} \mathrm{O}_{4}-0.4(\mathrm{Na} 0.5 \mathrm{Bi} 0.5) \mathrm{TiO}_{3}$. SEM micrograph of $\mathrm{NiFe}_{2} \mathrm{O}_{4}$ shows aggregation of micro-sized particles. The high dense agglomeration observed in micrometric particles indicates the presence of pore free crystallites on the surface of the sample. The morphology of Na..5Bio.5 $\mathrm{TiO}_{3}$ sample is seen to be spherical granules. The morphology of $0.6 \mathrm{NiFe}_{2} \mathrm{O}_{4}-0.4(\mathrm{Na} 0.5 \mathrm{Bi} 0.5) \mathrm{TiO}_{3}$ composite contains of mixture of both spherical and rectangular granules from parent phases. Further, energy dispersive X-ray analysis (EDX) is used (figure 2 (d)) to measure the elemental distribution and atomic percentage in $0.6 \mathrm{NiFe}_{2} \mathrm{O}_{4}$ $0.4\left(\mathrm{Na} 0.5 \mathrm{Bi}_{0.5}\right) \mathrm{TiO}_{3}$ composite. EXD spectra confirm the presence of all elements in the NFONBTO composite. However, due to high volatile nature of Bi, slight variation in its atomic percentage is observed. From the EDX data, the atomic percentage and mass percentage of each element in the NFO-NBTO composite is shown in table I.

Raman spectra of $\mathrm{NiFe}_{2} \mathrm{O}_{4}, \mathrm{Na} 0.5 \mathrm{Bi}_{0} .5 \mathrm{TiO}_{3}$ and $0.6 \mathrm{NiFe}_{2} \mathrm{O}_{4}-0.4(\mathrm{Na} 0.5 \mathrm{Bi} 0.5) \mathrm{TiO}_{3}$ composites are measured at room temperature and shown in figure 3 (a) to (c). Small incident laser power is used to identify all the Raman bands and the de-convoluted spectra are in Figure 3. The spectra 
of $\mathrm{NiFe}_{2} \mathrm{O}_{4}$ show five Raman bands at $699,334.5,211.3,485.2$ and $574.5 \mathrm{~cm}^{-1}$ correspond to $\mathrm{A}_{1 \mathrm{~g}}, \mathrm{E}_{\mathrm{g}}$, and $3 \mathrm{~T}_{2 \mathrm{~g}}$ bands respectively, which resemble the typical inverse spinel structure of $\mathrm{NiFe}_{2} \mathrm{O}_{4}$ phase. The observed five Raman active modes matches well with reports $[25,26]$. $\mathrm{NiFe}_{2} \mathrm{O}_{4}$ crystallizes in spinel structure of $\mathrm{Fd}-3 \mathrm{~m}$ space group. The observed peak at $209 \mathrm{~cm}^{-1}$ and $487 \mathrm{~cm}^{-1}$ ( $\mathrm{Eg}_{\mathrm{g}}$ mode) arises due to symmetric bending of $\mathrm{Fe}$ atoms at A site and asymmetric bending of oxygen atoms respectively. The symmetric stretching of oxygen in $\mathrm{Fe}-\mathrm{O}$ bond located at A site causes the $A_{1 g}$ Raman mode at $699 \mathrm{~cm}^{-1}$. The $t_{2 g}$ mode at $485.2 \mathrm{~cm}^{-1}$ gives rise to symmetric stretching of $\mathrm{Fe}-\mathrm{O}$ bond at $\mathrm{B}$ site. The Raman spectra of $\mathrm{Na}_{0.5} \mathrm{Bi}_{0.5} \mathrm{TiO}_{3}$ show a peak at $281.1 \mathrm{~cm}^{-1}$ corresponding to $\mathrm{A}_{1 \mathrm{~g}}$ mode and two other peaks at 526.2 and $579.6 \mathrm{~cm}^{-1}$ corresponding to $\mathrm{E}_{\mathrm{g}}$ mode. The peak at $280 \mathrm{~cm}^{-1}$ arises from $\mathrm{TiO}_{6}$ vibrations and the other peaks correspond to symmetric vibrations of oxygen in $\mathrm{Na}_{0.5} \mathrm{Bii}_{0.5} \mathrm{TiO}_{3}$. Figure 3 (c) shows the Raman spectra of $0.6 \mathrm{NiFe}_{2} \mathrm{O}_{4}-0.4\left(\mathrm{Na}_{0.5} \mathrm{Bi}_{0.5}\right) \mathrm{TiO}_{3}$ composites, exhibiting the modes corresponding to $\mathrm{NiFe}_{2} \mathrm{O}_{4}$ and $\mathrm{Na} 0.5 \mathrm{Bi}_{0.5} \mathrm{TiO}_{3}$ parent phases.

Chemical states of the elements and chemical bonding present in all the samples are explored using X-ray photoelectron spectroscopy (XPS). A high resolution spectra of Ni $2 p, \mathrm{Fe}$ $2 p, \mathrm{O} 1 s, \mathrm{Bi} 4 f$ and $\mathrm{Ti} 2 p$ elements of the $0.6 \mathrm{NiFe}_{2} \mathrm{O}_{4}-0.4(\mathrm{Na} 0.5 \mathrm{Bi} 0.5) \mathrm{TiO}_{3}$ composite is carried out using $\mathrm{Al} \mathrm{K}_{\alpha}$ radiation. The core level XPS spectra of all the elements are calibrated with the carbon binding energy of $284.6 \mathrm{eV}$. The survey spectrum is de-convoluted using mixed Gaussian and Lorentzian function (not shown). Survey spectra indicate the presence of all the elements. A core level spectrum of Ni $2 p$ is shown in figure 4 (a). Due to the spin-orbit coupling, the $2 p$ spectra of $\mathrm{Ni}$ split into two broad peaks which correspond to $2 p_{3 / 2}$ and $2 p_{1 / 2}$ energy levels 
centered around $\sim 854$ and $\sim 873 \mathrm{eV}$ respectively. The peaks centered at $860.9 \mathrm{eV}$ correspond to the satellite peak. The de-convolution spectra of nickel reveal the presence of three nonequivalent bonds. Two bonds correspond to two types of lattice sites for cations i.e., octahedral and tetrahedral while the third one is due to the presence of oxygen vacancy in the lattice. The binding energy associated with $\mathrm{Ni} 2 p_{3 / 2}$ are $854.4 \mathrm{eV}$ and $856.3 \mathrm{eV}$, which represents octahedral and tetrahedral bonding with oxygen and the oxidation state of $2+$. Similarly, the binding energies $873.0 \mathrm{eV}$ and $8763 \mathrm{eV}$ are correspond to octahedral and tetrahedral energies of Ni $2 p_{1 / 2}$ state respectively $[27,28]$. The core level XPS spectrum of Fe is shown in figure 4 (b). In the spectra peaks observed at $709.6 \mathrm{eV}, 711.2 \mathrm{eV}$ corresponds to the octahedral and tetrahedral bonding associated with $2 P_{3 / 2}$ and $724.9 \mathrm{eV}, 726.3 \mathrm{eV}$ corresponds to the state of $2 P_{1 / 2}$. The broader $\mathrm{Fe} 2 p$ peaks are observed in the present case due to the coordination of $\mathrm{Fe}^{+3}$ with oxygen in octahedral and tetrahedral geometries. The peaks centered at $718.5 \mathrm{eV}$ correspond to satellite peaks of Fe $[29,30]$. In the case of oxygen, the core-level spectrum of $\mathrm{O}$ $1 s$ is observed to be centered at $531 \mathrm{eV}$ which is attributed to the lattice oxygen atoms and the peak centered at $529 \mathrm{eV}$ is ascribed to the presence of oxygen vacancies (figure 4(c)) [31]. The peak observed at $531.7 \mathrm{eV}$ could be due to the chemisorbed oxygen lying on the surface of the samples and may simply be an artifact of fitting of asymmetric XPS peaks with symmetric Gaussian functions [32]. The core level $1 s$ spectrum of sodium is shown in figure 4(d). The presence of peak at $1071.3 \mathrm{eV}$ confirms the oxidation state of $\mathrm{Na}$ is +1 . The XPS spectra of Bi $4 f$ shown in figure 4(e) contains two peaks which are centered at $163.8 \mathrm{eV}$ and $158.4 \mathrm{eV}$, correspond to $4 f_{3 / 2}$ and $4 f_{5 / 2}$ states respectively. The de-convoluted spectrum of Ti $2 p$ is shown in figure 4(f). Due to the spin orbit coupling, $\mathrm{Ti}^{4+}$ splits into two peaks correspond to $\mathrm{Ti} 2 p_{1 / 2}$ and $\mathrm{Ti}$ $2 p_{3 / 2}$ centered at $457.6 \mathrm{eV}$ and $463.8 \mathrm{eV}$ respectively. The present XPS study reveals the 
oxidation state of all the elements and presence of oxygen vacancies in $0.6 \mathrm{NiFe}_{2} \mathrm{O}_{4}-0.4$ ( $\mathrm{Na} 0.5 \mathrm{Bi} 0.5) \mathrm{TiO}_{3}$ composite.

Magnetization measurements (M-H loop) are carried out for all the samples at various temperatures. The room temperature $\mathrm{MH}$ curve for pure $\mathrm{NiFe}_{2} \mathrm{O}_{4}, \mathrm{Na}_{0.5} \mathrm{Bi}_{0.5} \mathrm{TiO}_{3}$ and 0.6 $\mathrm{NiFe}_{2} \mathrm{O}_{4}-0.4\left(\mathrm{Na}_{0.5} \mathrm{Bi}_{0.5}\right) \mathrm{TiO}_{3}$ are shown in the of figure 5 (a), (b) and (c) respectively. It is observed that pure $\mathrm{NiFe}_{2} \mathrm{O}_{4}$ and the composite show the typical ferromagnetic behavior [33]. Saturation magnetization $\left(\mathrm{M}_{\mathrm{s}}\right)$ value of pure $\mathrm{NiFe}_{2} \mathrm{O}_{4}$ and $0.6 \mathrm{NiFe}_{2} \mathrm{O}_{4}-0.4\left(\mathrm{Na}_{0.5} \mathrm{Bi} 0.5\right) \mathrm{TiO}_{3}$ composite at RT is seen to be $59 \mathrm{emu} / \mathrm{g}$ and $25.72 \mathrm{emu} / \mathrm{g}$ respectively. Saturation magnetization value is seen to be lesser in case of composite compared to that of pure $\mathrm{NiFe}_{2} \mathrm{O}_{4}$ due to the presence of nonmagnetic $\mathrm{Na}_{0.5} \mathrm{Bi}_{0.5} \mathrm{TiO}_{3}$ phase. It is observed that the saturation magnetization (Ms) value (at $300 \mathrm{~K}$ is $25.7 \mathrm{emu} / \mathrm{g}$ ) increases with decreasing the temperature $(28 \mathrm{emu} / \mathrm{g}$ at 15 $\mathrm{K})$. Enhanced $\mathrm{Ms}_{\mathrm{s}}$ value at low temperatures is due to less thermal vibrations which randomizes the magnetic moments. [34 ]. M-H loops measured at 15, 150, 250 and $300 \mathrm{~K}$ for $0.6 \mathrm{NiFe}_{2} \mathrm{O}_{4}-$ $0.4(\mathrm{Na} 0.5 \mathrm{Bi} 0.5) \mathrm{TiO}_{3}$ composite is shown in figure 5(d). The remanent magnetization and coercivity values of $0.6 \mathrm{NiFe}_{2} \mathrm{O}_{4}-0.4\left(\mathrm{Na}_{0.5} \mathrm{Bi}_{0.5}\right) \mathrm{TiO}_{3}$ composites at different temperatures are shown in table II. It is found that the remanent magnetization and coercivity values increase from 2.51 to $3.36 \mathrm{emu} / \mathrm{g}$ and 47.7 to 62.3 Oe respectively with decreasing the temperature from $300 \mathrm{~K}$ to $15 \mathrm{~K}$. Increase in coercivity and remanence is due to the enhanced growth of magnetic anisotropy at lower temperatures. Increase in coercivity with decreasing temperature can be understood by considering the effects of thermal fluctuations of the blocked moment, across the anisotropy barrier. In the case of bulk ferromagnetic materials, the temperature dependent saturation magnetization $\left(\mathrm{M}_{\mathrm{s}}\right)$ is expressed by considering the simple model of thermal activation of particle moments over the anisotropy barriers as using Bloch's law [35]. The 
Bloch's law is framed by considering the excitations (magnon) are of long wave-length spinwaves at low temperature. For the bulk materials, Bloch's law is valid at low temperatures (i.e., $\mathrm{T}$ is less than $\left.\mathrm{T}_{\mathrm{C}} / 2\right)$ and is expressed as:

$$
\mathrm{Ms}_{\mathrm{S}}(\mathrm{T})=\mathrm{M}(0)\left[1-\left(\frac{T}{T_{0}}\right)^{\alpha}\right]
$$

where $\alpha$ is called as Bloch's exponent and its value for bulk material is $3 / 2 . M(0)$ is the magnetization at $\mathrm{T}=0 \mathrm{~K}$, which can be estimated by extrapolating the $\mathrm{Ms}_{\mathrm{s}}(\mathrm{T})$ versus $\mathrm{T}$ curve towards the $\mathrm{Y}$-axis. $\mathrm{T}_{0}$ is the temperature at which the saturation magnetization becomes zero, which can be estimated by extrapolating the Ms curve towards temperature axis. The best fit of the data to the model is shown in Figure 5 (e), with estimated M (0) and $\mathrm{T}_{0}$ values of $28.6 \mathrm{emu} / \mathrm{g}$ and $650 \mathrm{~K}$ respectively. Further, the law of approach to saturation (LAS) is employed to investigate the magnetic anisotropy constant values of $0.6 \mathrm{NiFe}_{2} \mathrm{O}_{4}-0.4\left(\mathrm{Na}_{0.5} \mathrm{Bi}_{0.5}\right) \mathrm{TiO}_{3}$ composite. According to the law of approach to saturation, the field dependence of magnetization close to saturation can be expressed as $[36,37]$ :

$$
\mathrm{M}=\mathrm{Ms}\left[1-\frac{b}{H^{2}}\right]+\kappa \mathrm{H}
$$

Where, $\mathrm{b}=\frac{8 K_{1}{ }^{2}}{105 \mu_{O} M_{S}{ }^{2}}$ and $\kappa \mathrm{H}$ is the forced magnetization coefficient. The value of $к \mathrm{H}$ is prominent at high fields and can be neglected at room temperature. The conditions for the above equation are $\mathrm{H}>>\mathrm{H}_{\mathrm{C}}$, and $\mathrm{T}<\mathrm{T}_{\mathrm{C}} / 2$. The magnetization $\mathrm{M}$ should be taken near to saturation, $\mu_{o}$ is permeabililty of free space $\left(1.257 \times 10^{-6} \mathrm{~kg} \cdot \mathrm{m} / \mathrm{s}^{2} \mathrm{~A}^{2}\right)$, and $K_{1}$ is the first order cubic magnetocrystalline anisotropy constant. Substitution of above values in equation (1) results to

$$
\mathrm{M}=\mathrm{MS}_{\mathrm{S}}\left[1-\frac{8 K_{1}{ }^{2}}{105 \mu_{O} M_{S}{ }^{2} H^{2}}\right]
$$


The magnetocrystalline anisotropy constants $\left(K_{1}\right)$ for the composite at different temperatures are calculated using equation (2) and are tabulated in table II. It is observed that the magnetocrystalline anisotropy increases from 0.23 to $0.34 \times 10^{4} \mathrm{erg} / \mathrm{cc}$ when the temperature is decreased from $300 \mathrm{~K}$ to $15 \mathrm{~K}$. The observed magnetocrystalline anisotropy values are lesser than the reported anisotropy values for $\mathrm{NiFe}_{2} \mathrm{O}_{4}$ and nanoparticles of NFO-NBTO composite at room temperature $[34,38,39]$. In the present case, $0.6 \mathrm{NiFe}_{2} \mathrm{O}_{4}-0.4\left(\mathrm{Na} 0.5 \mathrm{Bi}_{0.5}\right) \mathrm{TiO}_{3}$ particle size in the order of micron with wide size distribution. Therefore, the effect of particle size plays an important role in determining the anisotropy value.

Temperature dependent zero field cooled (ZFC) and field cool (FC) magnetization measurements are carried out to explore the magnetic interactions present in $0.6 \mathrm{NiFe}_{2} \mathrm{O}_{4}-0.4$ $\left(\mathrm{Na}_{0.5} \mathrm{Bi}_{0.5}\right) \mathrm{TiO}_{3}$ composite at low temperatures. Figure 5(f) shows the $\mathrm{ZFC}$ and $\mathrm{FC}$ magnetization recorded at 100 Oe field in the temperature range $15-300 \mathrm{~K}$. It is observed that the ZFC magnetic moment continuously decreases with decreasing temperature. FC magnetization is seen to increase slowly with decreasing temperature, indicating the weakly coupled magnetic system. At very low temperatures, FC magnetization is seen to decrease with decreasing the temperature indicating the presence of competing magnetic interactions. The ZFC and FC magnetization data is not to seen merge (irreversibility) up to the room temperature, indicating that the blocking temperature $\left(\mathrm{T}_{\mathrm{B}}\right)$ is well above the RT. Irreversibility between ZFC and FC at RT indicates that the anisotropy energy is greater than the thermal energy $\left(\mathrm{kB}_{\mathrm{B}} \mathrm{T}\right)$ below RT. In addition to that, the irreversibility can be attributed to the reduced antiferromagnetic interspin cluster interactions due to the orientation of few spin clusters along the field direction. Further, the strong super-exchange interaction between Fe ions at tetrahedral and octahedral sites leads to ferromagnetic Curie temperature $\left(\mathrm{T}_{\mathrm{C}}\right)$ well above the room temperature. Small hump in 
ZFC magnetization is seen to be present at $259.5 \mathrm{~K}$, noted as $\mathrm{T}_{\mathrm{m}}$, indicating the possibility of existance of short range ferromagnetic clusters which freezes into different metastable energy states. These short-range ferromagnetic clusters could couple with long range ferromagnetic phase. The decrease in ZFC magnetization below this hump is due to the random freezing of spin clusters into different metastable magnetic states [40-42].

\section{Conclusions}

The $0.6 \mathrm{NiFe}_{2} \mathrm{O}_{4}-0.4 \mathrm{Na} 0.5 \mathrm{Bi}_{0.5} \mathrm{TiO}_{3}$ composite is obtained by mixing inverse spinel $\mathrm{NiFe}_{2} \mathrm{O}_{4}$ and perovskite $\mathrm{Na}_{0.5} \mathrm{Bi}_{0.5} \mathrm{TiO}_{3}$ bulk materials in appropriate ratio. Micron size particles in all the materials are confirmed from scanning electron microscopy images. Oxidation states of all the elements are confirmed from XPS studies. Saturation magnetization, coercivity, remanent magnetization and magnetocrystalline anisotropy values of $0.6 \mathrm{NiFe}_{2} \mathrm{O}_{4}-0.4 \mathrm{Na} 0.5 \mathrm{Bi} 0.5 \mathrm{TiO}_{3}$ are seen to increase with decreasing temperature from $300 \mathrm{~K}$ to $15 \mathrm{~K}$. ZFC and FC magnetization measurement carried out from $300 \mathrm{~K}$ to $15 \mathrm{~K}$ reveals the existence of competing magnetic interaction in $0.6 \mathrm{NiFe}_{2} \mathrm{O}_{4}-0.4 \mathrm{Na} 0.5 \mathrm{Bi} 0.5 \mathrm{TiO}_{3}$ composite.

\section{Acknowledgement}

Authors thank the SRMIST for providing the Raman facilities 


\section{References}

[1] N. Ortega, A. Kumar, J.F. Scott, R.S. Katiyar, Multifunctional magnetoelectric materials for device applications, J. Phys. Condens. Matter. 27, 504002 (2015). https://doi.org/10.1088/0953-8984/27/50/504002.

[2] M.M. Vopson, Fundamentals of multiferroic materials and their possible applications,

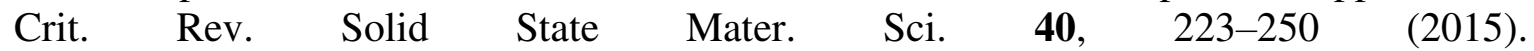
https://doi.org/10.1080/10408436.2014.992584.

[3] Z. Zhou, Q. Yang, M. Liu, Z. Zhang, X. Zhang, D. Sun, T. Nan, N. Sun, X. Chen, Antiferroelectric Materials, Applications and Recent Progress on Multiferroic Heterostructures, Spin, 5, 1-13 (2015). https://doi.org/10.1142/S2010324715300017.

[4] V.J. Folen, G.T. Rado, E.W. Stalder, Zx Yy, Phys. Rev. Lett. 6, 607-608 (1961).

[5] D. N. Astrov, Magnetoelectric effect in Chromium Oxide, Soviet Phys. J. Exptl. Theoret. Phys. 40, 1035-1041(1961).

[6] G.A. Smolenskii, I.E. Chupis, Ferroelectromagnets, Sov. Phys. - Uspekhi. 25, 415-448 (1982) https://doi.org/10.1070/PU1982v025n07ABEH004570.

[7] J. Wang, J.B. Neaton, H. Zheng, V. Nagarajan, S.B. Ogale, B. Liu, D. Viehland, V. Vaithyanathan, D.G. Schlom, U. V. Waghmare, N.A. Spaldin, K.M. Rabe, M. Wuttig, R. Ramesh, Epitaxial $\mathrm{BiFeO}_{3}$ multiferroic thin film heterostructures, Science (80-. ). 299 1719-1722 (2003). https://doi.org/10.1126/science.1080615.

[8] J. van den Boomgaard, R.A.J. Born, A sintered magnetoelectric composite material $\mathrm{BaTiO}_{3}-\mathrm{Ni}(\mathrm{Co}, \mathrm{Mn}) \mathrm{Fe}_{2} \mathrm{O}_{4}$, J. Mater.Sci., $\quad$ 13, 1538-1548 (1978). https://doi.org/10.1007/BF00553210.

[9] Van Suchtelen, Product Properties: A New Application of Composite Materials, Philips Res. Rep., 27, 28-37 (1972).

[10] J. Ryu, S. Priya, A.V. Carazo, K. Uchino, H.-E. Kim, Effect of the Magnetostrictive Layer on Magnetoelectric Properties in Lead Zirconate Titanate/Terfenol-D Laminate Composites, J. Am. Ceram. Soc. 84, 2905-2908 (2001). https://doi.org/10.1111/j.11512916.2001.tb01113.x.

[11] J. Ryu, S. Priya, K. Uchino, H. Kim, J. Electroceram, Magnetoelectric Effect in Composites of Magnetostrictive and Piezoelectric Materials, 8 ,107-119 (2002). 
[12] A. M. J. G. Van Run, D. R. Terrell, J. H. Scholing, An in situ grown eutectic magnetoelectric composite material, J. Mater. Sci. 9, 1710-1714 (1974).

[13] A.A. Zakharenko, A Study of New Nondispersive SH-SAWs in Magnetoelectroelastic Medium of Symmetry Class $6 \mathrm{~mm}$, Open J. Acoust. 05, 95-111 (2015). https://doi.org/10.4236/oja.2015.53009.

[14] H. Zheng, J. Wang, S.E. Lofland, Z. Ma, L. Mohaddes-Ardabili, T. Zhao, L. SalamancaRiba, S.R. Shinde, S.B. Ogale, F. Bai, D. Viehland, Y. Jia, D.G. Schlom, M. Wuttig, A. Roytburd, R. Ramesh, Multiferroic $\mathrm{BaTiO}_{3}-\mathrm{CoFe}_{2} \mathrm{O}_{4}$ Nanostructures, Science (80-. ). 303, 661-663 (2004). https://doi.org/10.1126/science.1094207.

[15] X.H. Wang, X.Y. Deng, H.L. Bai, H. Zhou, W.G. Qu, L.T. Li, I.W. Chen, Two-step sintering of ceramics with constant grain-size, II: $\mathrm{BaTiO}_{3}$ and $\mathrm{Ni}-\mathrm{Cu}-\mathrm{Zn}$ ferrite, J. Am. Ceram. Soc. 89, 438-443 (2006). https://doi.org/10.1111/j.1551-2916.2005.00728.x.

[16] W. Eerenstein, N.D. Mathur, J.F. Scott, Multiferroic and magnetoelectric materials, Nature. 442, 759-765 (2006). https://doi.org/10.1038/nature05023.

[17] M. Zeng, J.G. Wan, Y. Wang, H. Yu, J.M. Liu, X.P. Jiang, C.W. Nan, Resonance magnetoelectric effect in bulk composites of lead zirconate titanate and nickel ferrite, J. Appl. Phys. 95, 8069-8073 (2004). https://doi.org/10.1063/1.1739531.

[18] Y. Saito, H. Takao, T. Tani, T. Nonoyama, K. Takatori, T. Homma, T. Nagaya, M. Nakamura, Lead-free peizoceramics, Nautre 432, 7013 : 84-7 (2004) doi: $\underline{10.1038 / \text { nature } 03028}$

[19] X.G. Tang, J. Wang, X.X. Wang, H.L.W. Chan, Preparation and electrical properties of highly (111)-oriented $\left(\mathrm{Na}_{0.5} \mathrm{Bi}_{0.5}\right) \mathrm{TiO}_{3}$ thin films by a sol-gel process, Chem. Mater. 16, 5293-5296 (2004). https://doi.org/10.1021/cm0352221.

[20] P. I. Slick, Ferromagnetic Materials, North-Holland, Amsterdam, Vol.2 ,1 (1980)

[21] S. Narendra Babu, S. Gi Min, L. Malkinski, Electric field tunable magnetic properties of lead-free $\mathrm{Na} 0.5 \mathrm{Bi}_{0.5} \mathrm{TiO}_{3} / \mathrm{CoFe}_{2} \mathrm{O}_{4}$ multiferroic composites, J. Appl. Phys. 109, 20132016 (2011). https://doi.org/10.1063/1.3544500.

[22] S. Narendra Babu, L. Malkinski, Large converse magnetoelectric effect in $\mathrm{Na}_{0.5} \mathrm{Bi}_{0.5} \mathrm{TiO}_{3-}$ $\mathrm{CoFe}_{2} \mathrm{O}_{4}$ lead-free multiferroic composites, J. Appl. Phys. 111, 5-8 (2012). https://doi.org/10.1063/1.3679054.

[23] S. Narendra Babu, J.H. Hsu, Y.S. Chen, J.G. Lin, Magnetoelectric response in lead-free multiferroic $\mathrm{NiFe}_{2} \mathrm{O}_{4}-\mathrm{Na}_{0.5} \mathrm{Bi}_{0.5} \mathrm{TiO}_{3}$ composites, J. Appl. Phys. 109, 107-110 (2011). https://doi.org/10.1063/1.3540623 
[24] W. Wang, Z. Ding, X. Zhao, S. Wu, F. Li, M. Yue, J. Ping Liu Microstructure and magnetic properties of $\mathrm{MFe}_{2} \mathrm{O}_{4}(\mathrm{M}=\mathrm{Co}, \mathrm{Ni}$, and $\mathrm{Mn})$ ferrite nanocrystals prepared using collid mill and hydrothermal method, J. Appl. Phys. 117, 17A328 (2015). https://doi.org/10.1063/1.4917463

[25] S. Umashankar, T. Parida, K. Ramesh Kumar, A.M. Strydom, G. Markandeyulu, K. Kamala Bharathi, Competing magnetic interactions and superparamagnetism like behaviour in $\mathrm{xNiFe}_{2} \mathrm{O}_{4}-(1-\mathrm{x}) \mathrm{BaTiO}_{3}(\mathrm{x}=0.2$ and 0.3$)$ nano composites, J. Magn. Magn. Mater. 439, 213-219 (2017). https://doi.org/10.1016/j.jmmm.2017.05.002.

[26] A. Ahlawat, V.G. Sathe, Raman study of $\mathrm{NiFe}_{2} \mathrm{O}_{4}$ nanoparticles, bulk and films: Effect of laser power, J. Raman Spectrosc. 42, 1087-1094 (2011). https://doi.org/10.1002/jrs.2791.

[27] G.C. Allen, S.J. Harris, J.A. Jutson, J.M. Dyke, A study of a number of mixed transition metal oxide spinels using X-ray photoelectron spectroscopy, Appl. Surf. Sci. 37, 111-134 (1989). https://doi.org/10.1016/0169-4332(89)90977-X.

[28] G.H. Jaffari, A.K. Rumaiz, J.C. Woicik, S.I. Shah, Influence of oxygen vacancies on the electronic structure and magnetic properties of $\mathrm{NiFe}_{2} \mathrm{O}_{4}$ thin films, J. Appl. Phys. 111 (2012). https://doi.org/10.1063/1.4704690.

[29] M. Lenglet, F. Hochu, J. Dürr, M.H. Tuilier, Investigation of the chemical bonding in 3d8 nickel(II) charge transfer insulators (NiO, oxidic spinels) from ligand-field spectroscopy, Ni 2p XPS and X-ray absorption spectroscopy, Solid State Commun. 104, 793-798 (1997). https://doi.org/10.1016/S0038-1098(97)00273-1.

[30] Z. Zhou, Y. Zhang, Z. Wang, W. Wei, W. Tang, J. Shi, R. Xiong, Electronic structure studies of the spinel $\mathrm{CoFe}_{2} \mathrm{O}_{4}$ by X-ray photoelectron spectroscopy, Appl. Surf. Sci. 254 6972-6975 (2008). https://doi.org/10.1016/j.apsusc.2008.05.067.

[31] S. Diodati and S. Gross, Coprecipitated Transition Metal Ferrites Investigated by XPS, Surface Sci. Spect. 20, 17-34 (2013).

[32] J.G. Kim, D.L. Pugmire, D. Battaglia, M.A. Langell, Analysis of the NiCo2O4 spinel surface with Auger and X-ray photoelectron spectroscopy, Appl. Surf. Sci. 165, 70-84 (2000). https://doi.org/10.1016/S0169-4332(00)00378-0.

[33] M. Rawat, K.L. Yadav, Electrical, magnetic and magnetodielectric properties in ferriteferroelectric particulate composites, Smart Mater. Struct. 24, 45041 (2015). https://doi.org/10.1088/0964-1726/24/4/045041.

[34] M. Sarathbavan, H.K. Dara, K.R. Kumar, A.M. Strydom, T. Parida, K. Ramamurthi, K.K. Bharathi, Effect of $\alpha$-Fe 2 O 3 Phase on the Magnetic Interactions in Nickel Ferrite $\left(\mathrm{NiFe}_{2} \mathrm{O}_{4}\right)$ Nanoparticles , J. Nanosci. Nanotechnol. 19, $5692-5699$ (2019). https://doi.org/10.1166/jnn.2019.16528. 
[35] Von F. Bloch, On the theory of ferromagnetism, Z. Physik 61, 206-219 (1930). https://doi.org/10.1007/BF01339661

[36] W. F. Brown, Effect of Dislocations on Magnetization Near Saturation, Phys. Rev. 60 139-147 (1941).

[37] L. N'eel, Relation between the Anisotropy constant and the Law of Approach to Saturation of ferromagnetic J. Phys. Radium 9, 193-199 (1948).

[38] M. Sarathbavan, H. Kumar Dara, T. Parida, K. Ramamurthi, K. Kamala Bharathi, Competing magnetic interactions, low and high temperature magnetic properties of $0.3 \mathrm{NiFe}_{2} \mathrm{O}_{4}-0.7 \mathrm{Na} 0.5 \mathrm{Bi}_{0.5} \mathrm{TiO}_{3}$ nanocomposites, J. Magn. Magn. Mater. 491, 165627 (2019). https://doi.org/10.1016/j.jmmm.2019.165627.

[39] K. Ugendar, V.R. Reddy, G. Markandeyulu, Temperature Dependence of Magnetization, Anisotropy, and Hyperfine Fields of $\mathrm{NiFe}_{2-\mathrm{x}} \mathrm{Yb}_{\mathrm{x}} \mathrm{O}_{4}(\mathrm{x}=0$, 0.05, 0.075), IEEE Trans. Magn. 52, 3-8 (2016). https://doi.org/10.1109/TMAG.2015.2473819.

[40] K.K. Bharathi, R.J. Tackett, C.E. Botez, C. V. Ramana, Coexistence of spin glass behavior and long-range ferrimagnetic ordering in La- and Dy-doped Co ferrite, J. Appl. Phys. 109, 2012-2015(2011). https://doi.org/10.1063/1.3562201.

[41] D. Fiorani, S. Viticoli, Magnetic properties of the antiferromagnetic frustrated system $\mathrm{ZnCr}_{2} \mathrm{XGa}_{2-2 \mathrm{O}} \mathrm{O}_{4}$, J. Magn. Magn. Mater. 49, 83-92 (1985). https://doi.org/10.1016/0304$\underline{8853(85) 90105-2 .}$.

[42] K. H. Fisher and J. A. Hertz, Spin Glasses, Cambridge University Press, New York, (1991) 


\section{Figure captions}

Figure 1 X-ray diffraction patterns of $\mathrm{NiFe}_{2} \mathrm{O}_{4}$ (a), $\mathrm{Na}_{0.5} \mathrm{Bi}_{0.5} \mathrm{TiO}_{3}$ (b) and $0.6 \mathrm{NiFe}_{2} \mathrm{O}_{4}$ $0.4 \mathrm{Na}_{0.5} \mathrm{Bi}_{0.5} \mathrm{TiO}_{3}$ (c) composite. Composite shows all the peaks corresponding to both $\mathrm{NiFe}_{2} \mathrm{O}_{4}$ and $\mathrm{Na}_{0.5} \mathrm{Bi}_{0.5} \mathrm{TiO}_{3}$ phases.

Figure 2 SEM images of $\mathrm{NiFe}_{2} \mathrm{O}_{4}$ (a), $\mathrm{Na}_{0.5} \mathrm{Bi}_{0.5} \mathrm{TiO}_{3}$ (b) and the $0.6 \mathrm{NiFe}_{2} \mathrm{O}_{4}-0.4$ $\mathrm{Na} 0.5 \mathrm{Bi}_{0.5} \mathrm{TiO}_{3}$ composite (c). EDX spectra of the composite shows all the elements present in the composite.

Figure 3 Room temperature Raman spectra of $\mathrm{NiFe}_{2} \mathrm{O}_{4}$ (a), $\mathrm{Na}_{0.5} \mathrm{Bi}_{0.5} \mathrm{TiO}_{3}$ (b) and $0.6 \mathrm{NiFe}_{2} \mathrm{O}_{4}-0.4 \mathrm{Na}_{0.5} \mathrm{Bi}_{0.5} \mathrm{TiO}_{3}$ (c) composite

Figure 4 The X-ray Photoelectron spectroscopy of the $0.6 \mathrm{NiFe}_{2} \mathrm{O}_{4}-0.4 \mathrm{Na}_{0.5} \mathrm{Bi}_{0.5} \mathrm{TiO}_{3}$ composite .core level spectra of Ni $2 p$ (a), Fe $2 p$ (b), O $1 s$ (c), Na $1 s$ (d), Bi $4 f$ (e), and $\mathrm{Ti} 2 p$ (f). The peaks are deconvoluted using combined GaussianLorentzian distribution function.

Figure 5 Field dependent magnetization curves of pure $\mathrm{NiFe}_{2} \mathrm{O}_{4}(\mathbf{a}), \mathrm{Na}_{0.5} \mathrm{Bi}_{0.5} \mathrm{TiO}_{3}(\mathbf{b})$ and $0.6 \mathrm{NiFe}_{2} \mathrm{O}_{4}-0.4 \mathrm{Na}_{0.5} \mathrm{Bi}_{0.5} \mathrm{TiO}_{3}$ (c) at room temperature. Magnetization curves of $0.6 \mathrm{NiFe}_{2} \mathrm{O}_{4}-0.4 \mathrm{Na}_{0.5} \mathrm{Bi}_{0.5} \mathrm{TiO}_{3}$ composite at various temperatures (d). Temperature variation of saturation magnetization and the curve fit using Bloch's law (e). Zero field cooled and field cooled magnetization curve of $0.6 \mathrm{NiFe}_{2} \mathrm{O}_{4}-$ $0.4 \mathrm{Na} 0.5 \mathrm{Bi} 0.5 \mathrm{TiO}_{3}$ composite measured at $100 \mathrm{Oe}$ in the temperature interval $15 \mathrm{~K}$ to $300 \mathrm{~K}$ (f). 
Figure 1

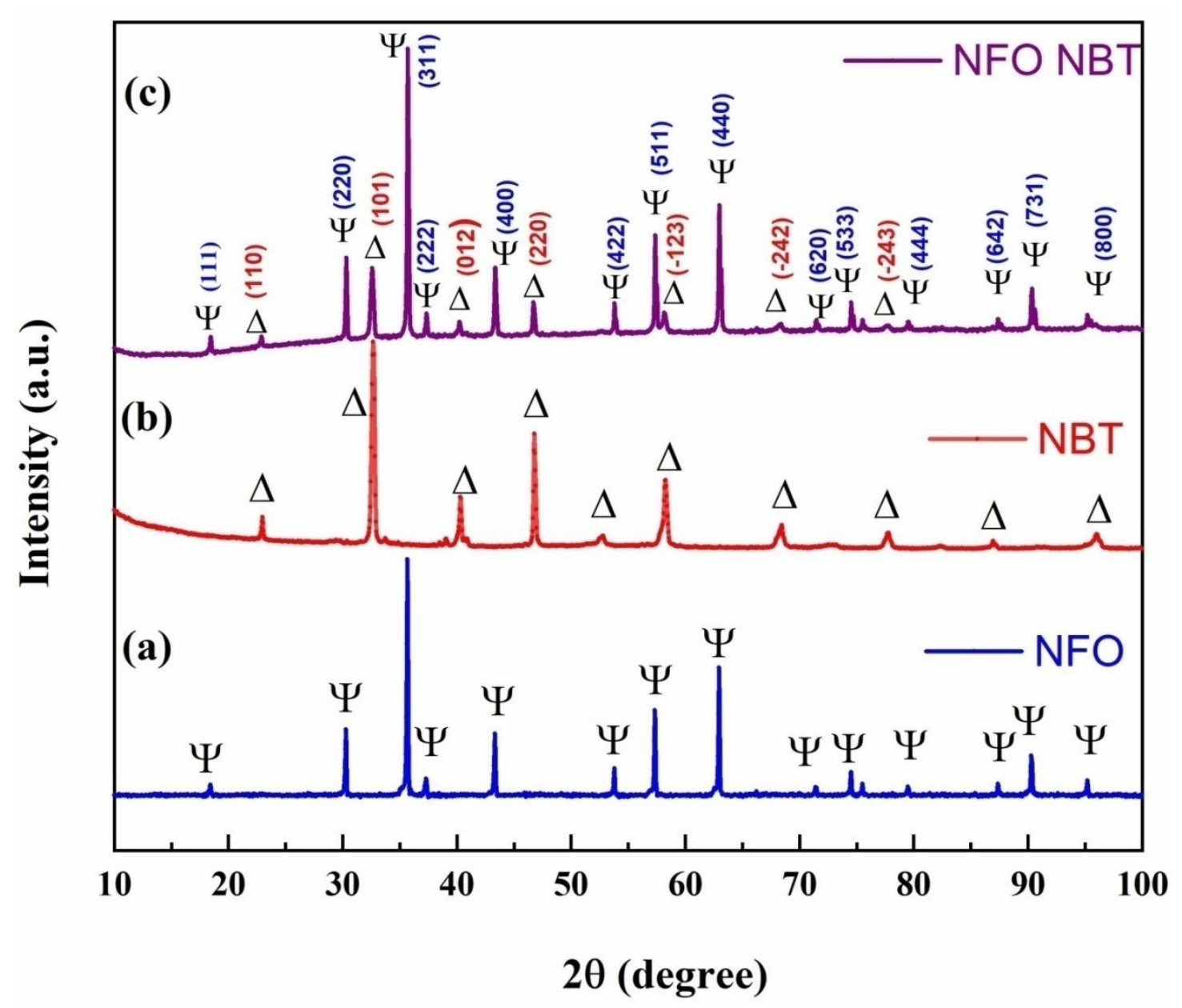


Figure 2
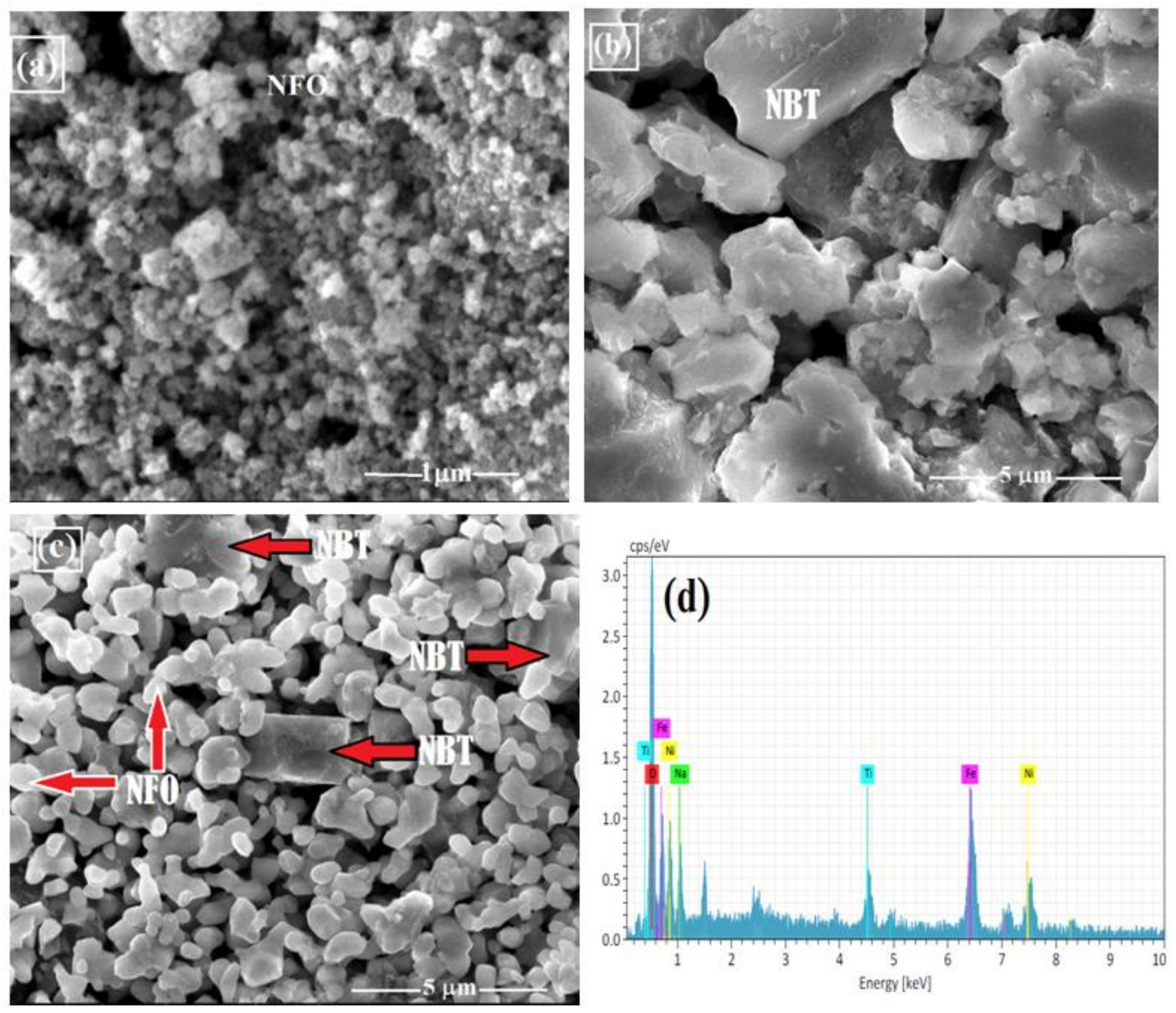
Figure 3

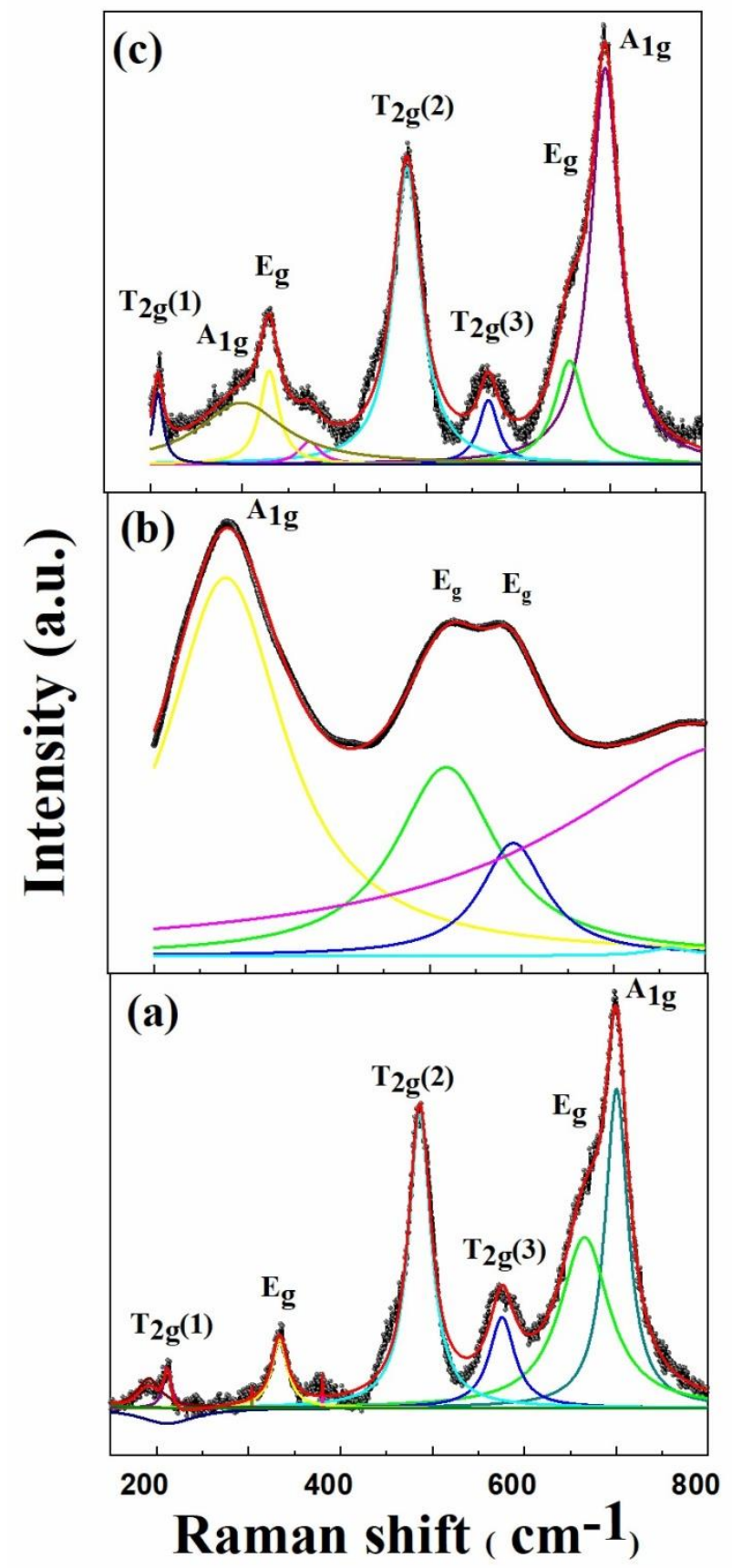




\section{Figure 4}
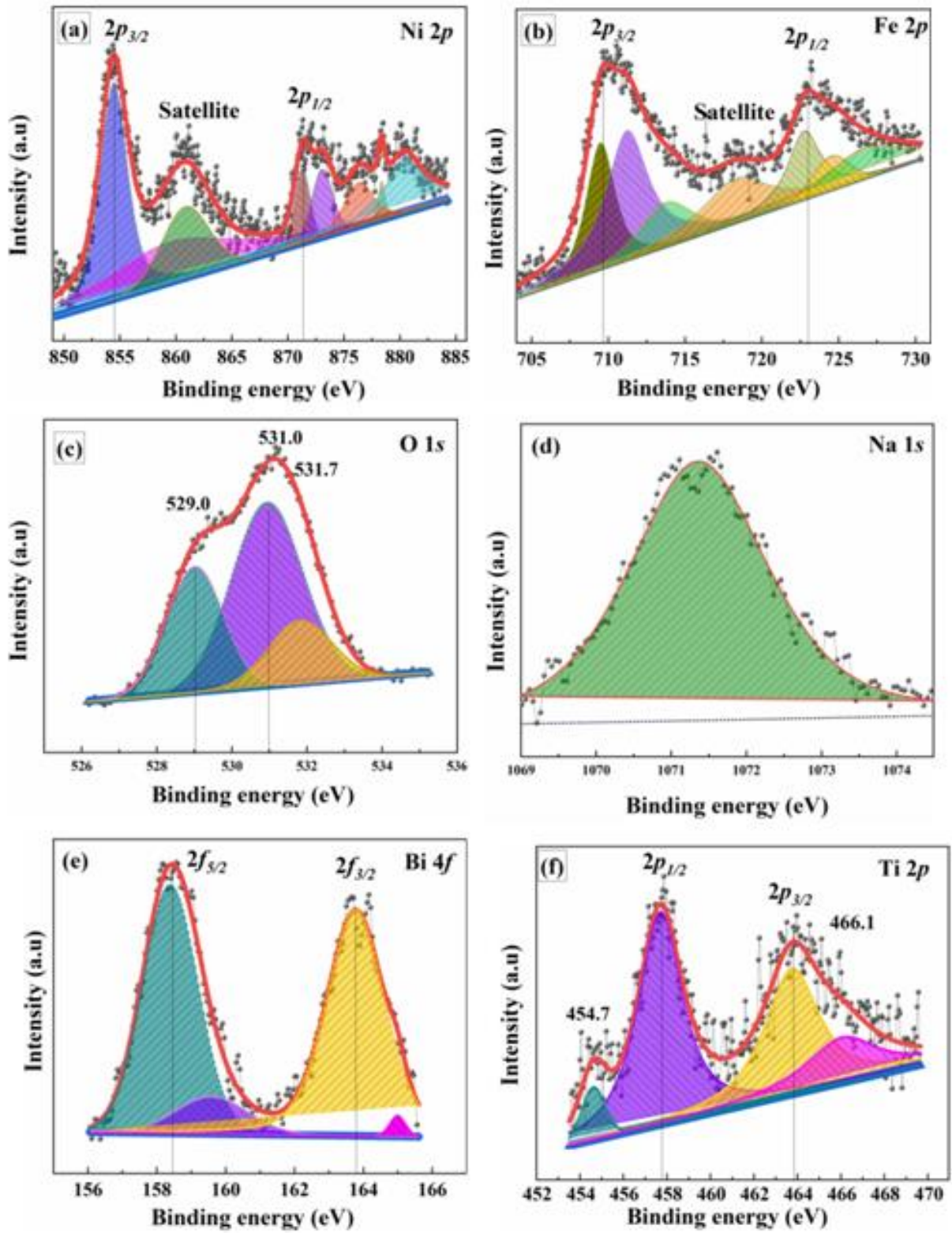


\section{Figure 5}
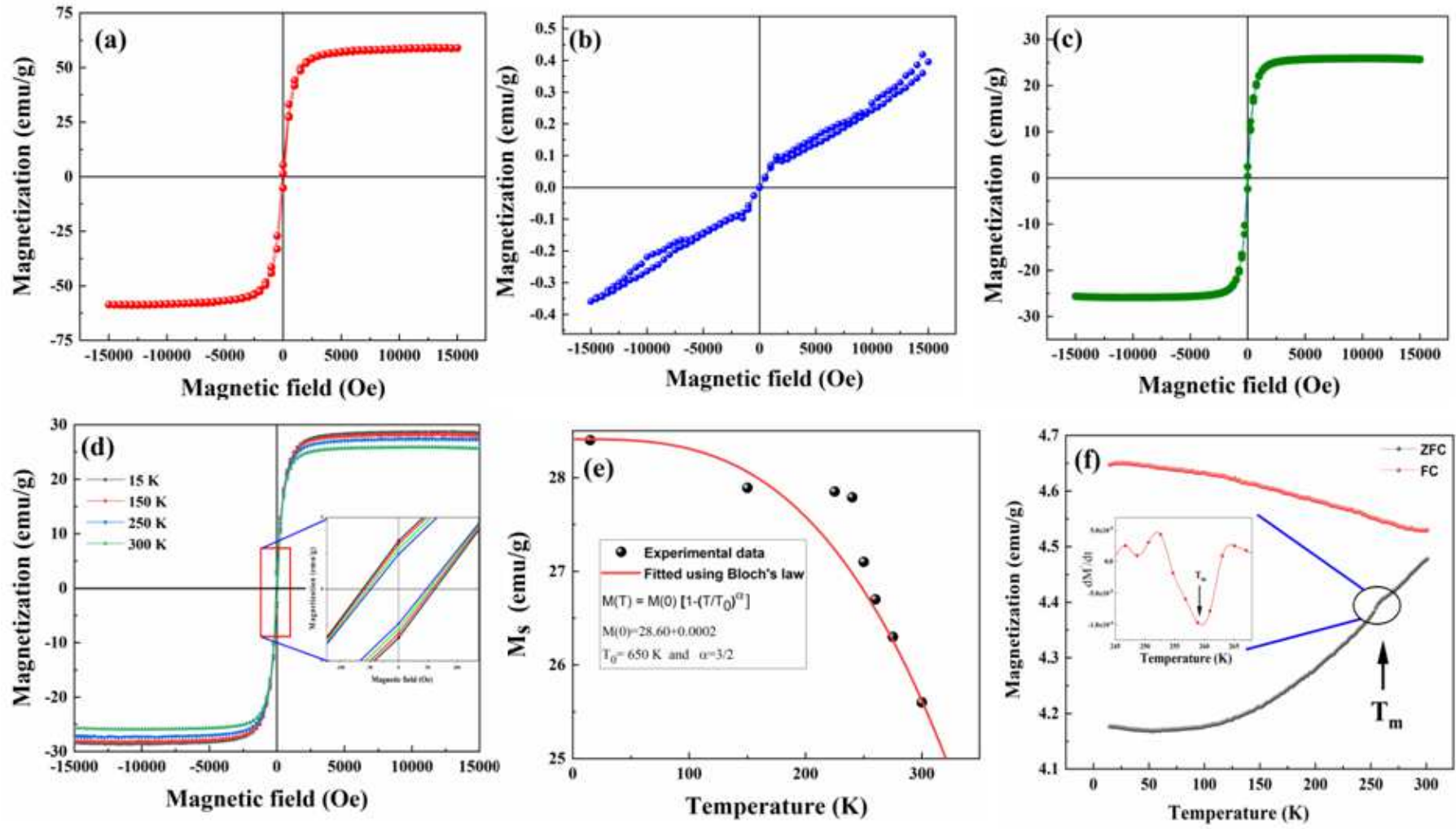
Table I: The elemental distribution and relative atomic percentage of $0.6 \mathrm{NiFe}_{2} \mathrm{O}_{4}$ $0.4 \mathrm{Na} 0.5 \mathrm{Bi}_{0.5} \mathrm{TiO}_{3}$ composite using EDX.

\begin{tabular}{|c|c|c|c|c|}
\hline Element & Atomic & Mass & Atomic & Absolute \\
& number & $(\boldsymbol{\%})$ & $(\boldsymbol{\%})$ & error $(\boldsymbol{\%})$ \\
& & & & $(\mathbf{1}$ sigma $)$ \\
\hline $\mathrm{Fe}$ & 26 & 64.13 & 47.91 & 3.74 \\
\hline $\mathrm{O}$ & 8 & 11.94 & 31.13 & 2.32 \\
\hline $\mathrm{Ti}$ & 22 & 9.47 & 8.25 & 0.63 \\
\hline $\mathrm{Ni}$ & 28 & 6.79 & 4.82 & 1.85 \\
\hline $\mathrm{Na}$ & 11 & 4.34 & 7.88 & 0.45 \\
\hline $\mathrm{Bi}$ & 83 & 1.12 & 0.01 & 0.10 \\
\hline
\end{tabular}


Table II: Saturation magnetization (Ms) value, remenant magnetization, coercivity, $\mathrm{M}_{\mathrm{r}} / \mathrm{M}_{\mathrm{s}}$ and magnetocrystalline anisotropy values at various temperature.

\begin{tabular}{|c|c|c|c|c|c|}
\hline Temperature & Saturation & Remanence & Coercivity & & Magnetocrystalline \\
& Magnetization & $\mathbf{M}_{\mathbf{r}}$ & $\mathbf{H}_{\mathbf{C}}$ & $\mathbf{M}_{\mathbf{r}} / \mathbf{M}_{\mathbf{S}}$ & $\mathbf{a n i s o t r o p y}\left(\mathbf{K}_{\mathbf{1}}\right)$ \\
& $\mathbf{M}_{\mathbf{S}}(\mathbf{e m u} / \mathbf{g})$ & $(\mathbf{e m u} / \mathbf{g})$ & $\mathbf{( O e})$ & & $\mathbf{x 1 0} \mathbf{e r g} / \mathbf{c c}$ \\
\hline $15 \mathrm{~K}$ & 28.58 & 3.36 & 62.3 & 0.12 & 0.34 \\
\hline $150 \mathrm{~K}$ & 28.16 & 3.13 & 57.8 & 0.11 & 0.30 \\
\hline $250 \mathrm{~K}$ & 27.28 & 2.81 & 52.9 & 0.10 & 0.28 \\
\hline $300 \mathrm{~K}$ & 25.72 & 2.51 & 47.7 & 0.09 & 0.23 \\
\hline
\end{tabular}


Figures

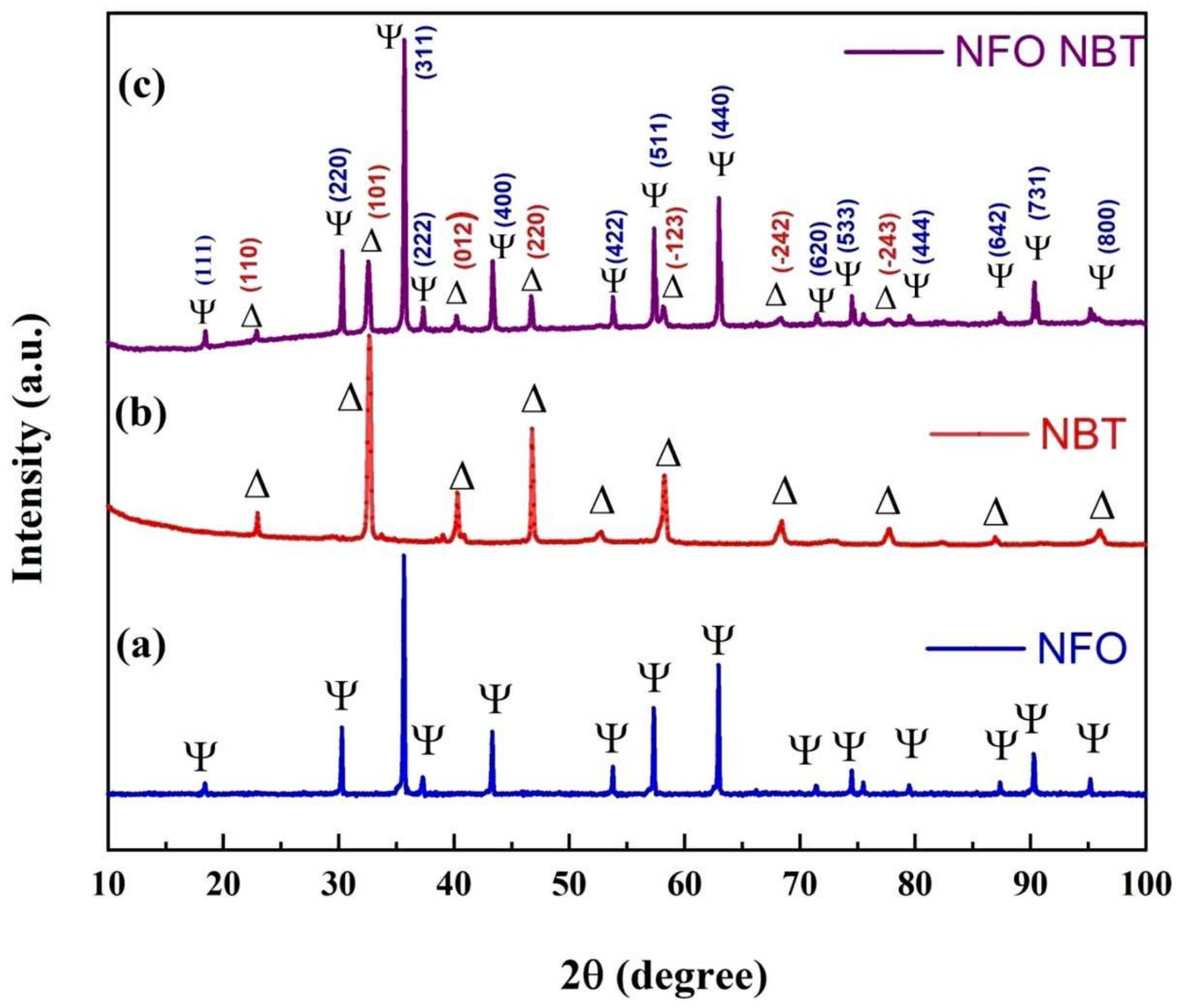

Figure 1

X-ray diffraction patterns of NiFe2O4 (a), Na0.5Bi0.5TiO3 (b) and 0.6NiFe2O4-0.4Na0.5Bi0.5TiO3 (c) composite. Composite shows all the peaks corresponding to both NiFe2O4 and Na0.5Bi0.5TiO3 phases. 

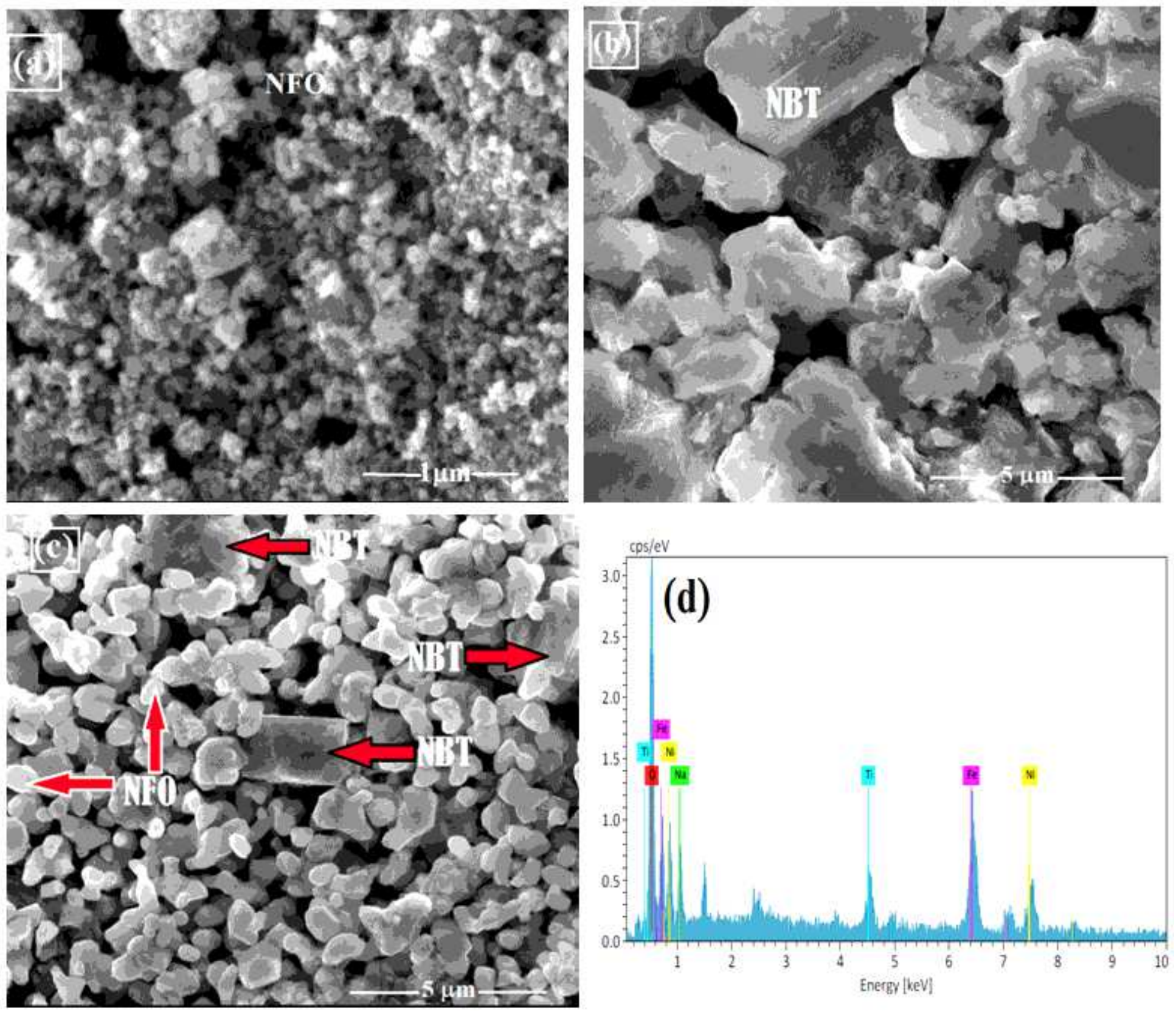

Figure 2

SEM images of NiFe2O4 (a), Na0.5Bi0.5TiO3 (b) and the 0.6 NiFe2O4-0.4 Na0.5Bi0.5TiO3 composite (c). EDX spectra of the composite shows all the elements present in the composite. 


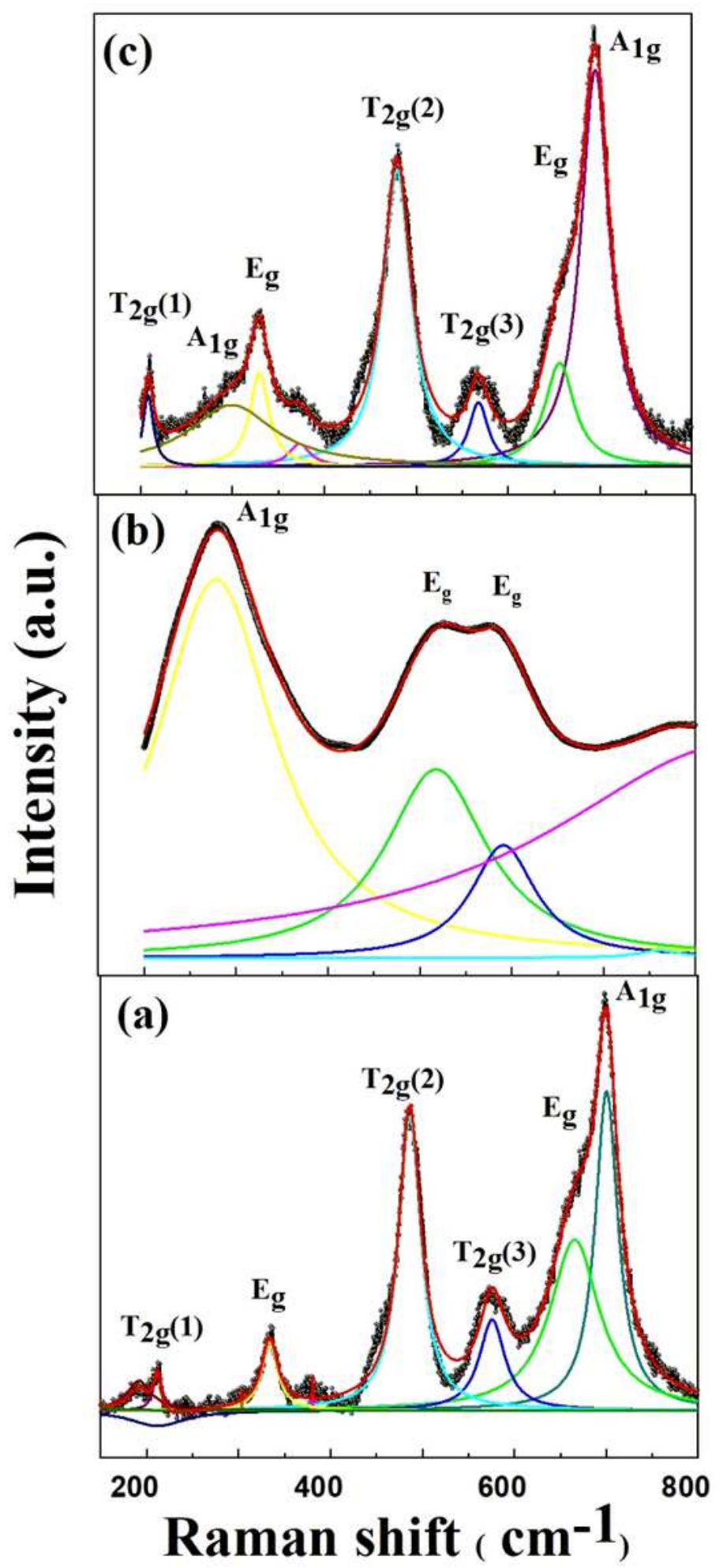

Figure 3

Room temperature Raman spectra of NiFe2O4 (a), Na0.5Bi0.5TiO3 (b) and 0.6NiFe2O4$0.4 \mathrm{Na0} .5 \mathrm{Bi0} .5 \mathrm{TiO} 3$ (c) composite 

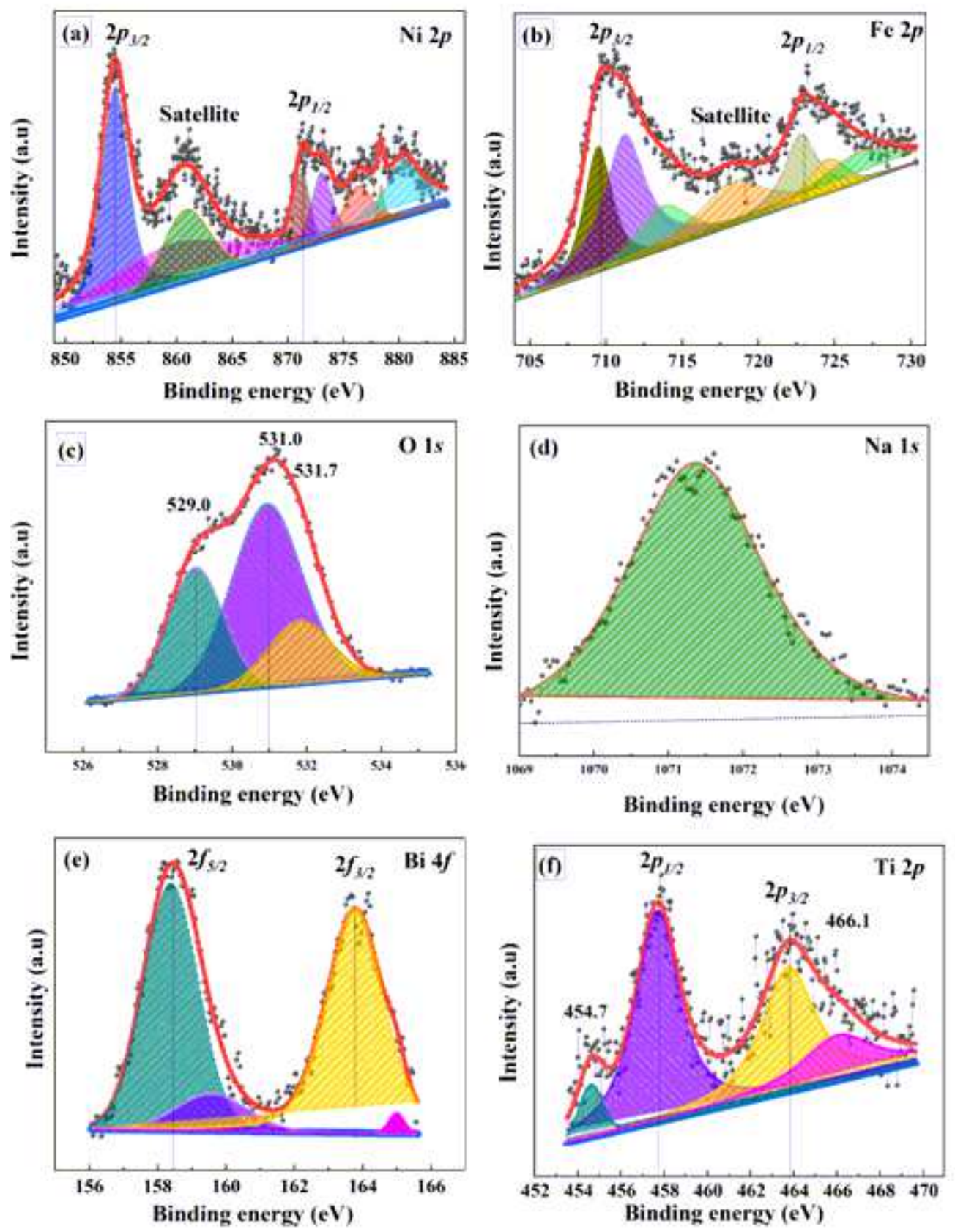

\section{Figure 4}

The X-ray Photoelectron spectroscopy of the $0.6 \mathrm{NiFe} 2 \mathrm{O} 4-0.4 \mathrm{Na} 0.5 \mathrm{Bi0} 0.5 \mathrm{TiO} 3$ composite .core level spectra of Ni 2p (a), Fe 2p (b), O 1s (c), Na 1s (d), Bi 4f (e), and Ti 2p (f). The peaks are deconvoluted using combined Gaussian-Lorentzian distribution function. 

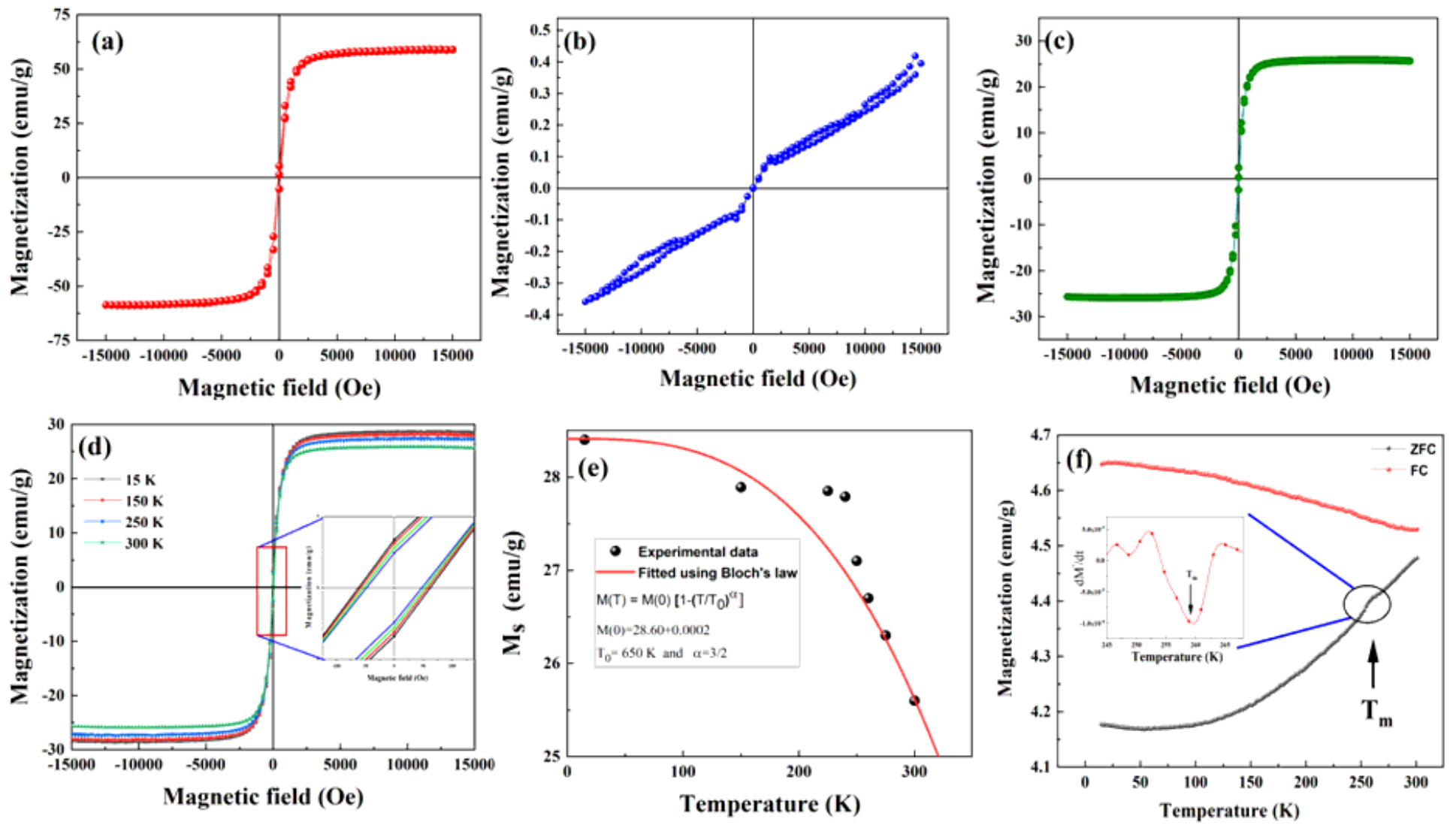

Figure 5

Field dependent magnetization curves of pure NiFe2O4 (a), Na0.5Bi0.5TiO3 (b) and 0.6NiFe2O4$0.4 \mathrm{Na} 0.5 \mathrm{Bi0} .5 \mathrm{TiO} 3$ (c) at room temperature. Magnetization curves of $0.6 \mathrm{NiFe} 2 \mathrm{O} 4-0.4 \mathrm{Na} 0.5 \mathrm{Bi} 0.5 \mathrm{TiO}$ composite at various temperatures (d). Temperature variation of saturation magnetization and the curve fit using Bloch's law (e). Zero field cooled and field cooled magnetization curve of 0.6NiFe204$0.4 \mathrm{Na} 0.5 \mathrm{Bi0} 0.5 \mathrm{TiO} 3$ composite measured at $100 \mathrm{Oe}$ in the temperature interval $15 \mathrm{~K}$ to $300 \mathrm{~K}(\mathrm{f})$. 